\title{
Laser Induced Modification of the Optical Properties of Nano-ZnO Doped PVC Films
}

\author{
Tagreed K. Hamad, ${ }^{1}$ Rahimi M. Yusop, ${ }^{2}$ Wasan A. Al-Taa'y, \\ Bashar Abdullah, ${ }^{3}$ and Emad Yousif ${ }^{4}$ \\ ${ }^{1}$ Department of Physics, College of Science, Al-Nahrain University, Baghdad, Iraq \\ ${ }^{2}$ School of Chemical Sciences \& Food Technology, Faculty of Science and Technology, Universiti Kebangsaan Malaysia, \\ 43600 Bangi, Selangor, Malaysia \\ ${ }^{3}$ Clinical Investigation Centre, University Malaya Medical Centre, 13th Floor, Main Tower, Lembah Pantai, \\ 59100 Kuala Lumpur, Malaysia \\ ${ }^{4}$ Department of Chemistry, College of Science, Al-Nahrain University, Baghdad, Iraq
}

Correspondence should be addressed to Rahimi M. Yusop; rahimi@ukm.my

Received 15 June 2014; Revised 12 September 2014; Accepted 14 September 2014; Published 14 October 2014

Academic Editor: Miriam Rafailovich

Copyright (C) 2014 Tagreed K. Hamad et al. This is an open access article distributed under the Creative Commons Attribution License, which permits unrestricted use, distribution, and reproduction in any medium, provided the original work is properly cited.

\begin{abstract}
The effect of continuous $\mathrm{CO}_{2}$ laser radiation on the optical properties of pure polyvinyl chloride and doped of $\mathrm{ZnO}$ nanoparticles with two different concentrations $(10,15 \%)$ has been investigated. All samples were prepared using casting method at room temperature. Optical properties (absorption, transmission, absorption coefficient, extinction coefficient, refractive index, and optical conductivity) of all films after $\mathrm{CO}_{2}$ laser irradiated have been studied as a function of the wavelength in the range (200$800) \mathrm{nm}$ for three energies $(300,400$ and $500 \mathrm{~mJ}$ ). It has been found that the transmission, energy gap, and refractive index increase with increasing laser energy. The values of absorption, Urbach energy, absorption coefficient, extinction coefficient, and optical conductivity were decreased.
\end{abstract}

\section{Introduction}

In recent years, polymer nanocomposites and understanding their physical and chemical properties have attracted great attention $[1,2]$. The presence of nanoparticles in polymer improves the mechanical, electrical, and optical properties of the materials [3]; metal oxide nanoparticles doped polymers have been studied as alternative materials for optical applications such as planar waveguide devices and microoptical elements [4]. Many polymers have been proved to be suitable matrices in the development of composite structures due to their ease of production and processing, good adhesion with reinforcing elements, resistance to corrosive environment, light weight, and in some cases ductile mechanical performance $[5,6]$.

$\mathrm{ZnO}$ has been one of the most promising materials for electrical devices, including transparent conductive films, light emitting diodes, photocatalyst, and solar cells $[7,8]$.
Moreover, because it has been chemically and optically stable and has a low toxicity, its use as a fluorescent label for bioimaging has been anticipated when using nanoparticles for biomedical purposes [9].

On the other hand, a lot of research work $[10,11]$ is underway on the effect of laser irradiation, annealing, ultraviolet irradiation, $\gamma$-irradiation, and so forth on optical and electrical properties of polymeric material. A high power $\mathrm{CO}_{2}$ laser is frequently used for cutting and welding, while lower powered devices are used for engraving. Polymer [12] waveguides have been fabricated by $\mathrm{CO}_{2}$ laser ablation, which is a pure photothermal effect, occurring at an energy density above a threshold [13]. There is, however, no detailed report of any optical property modifications of polymer induced by $\mathrm{CO}_{2}$ laser radiation at an energy density below the ablation threshold.

In the present work, zinc oxide $(\mathrm{ZnO})$ doped PVC thin films have been prepared using a well-known casting method; 


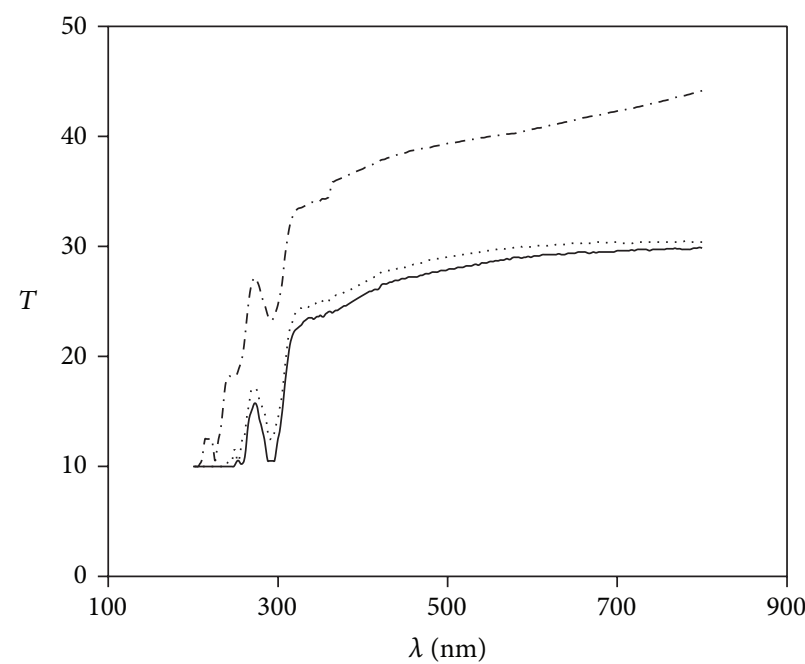

$\begin{array}{cc}\mathrm{A} 1 \\ \cdots & \mathrm{B} 1\end{array}$ $\cdot-\cdot-\mathrm{C} 1$

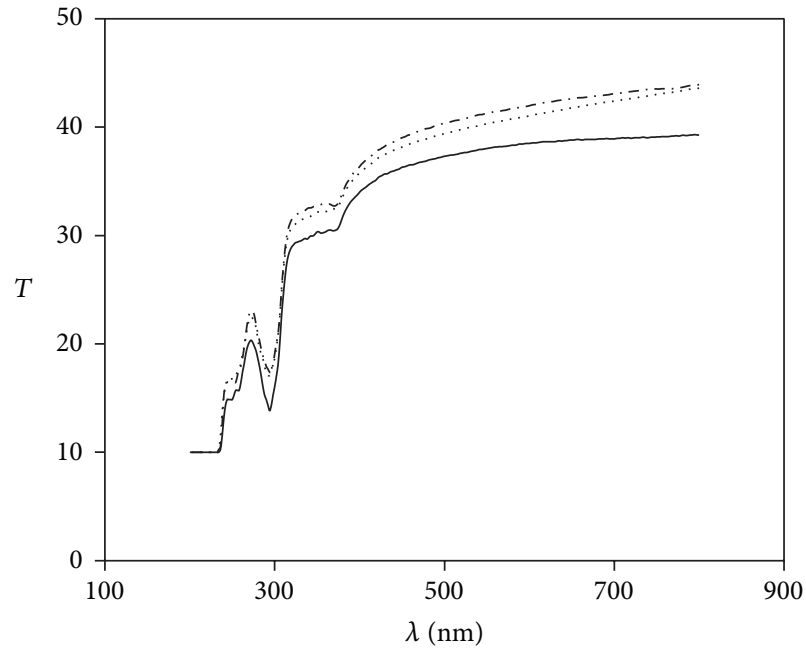

- A4

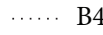

$\cdot-\cdot-\mathrm{C} 4$

(a)

(b)

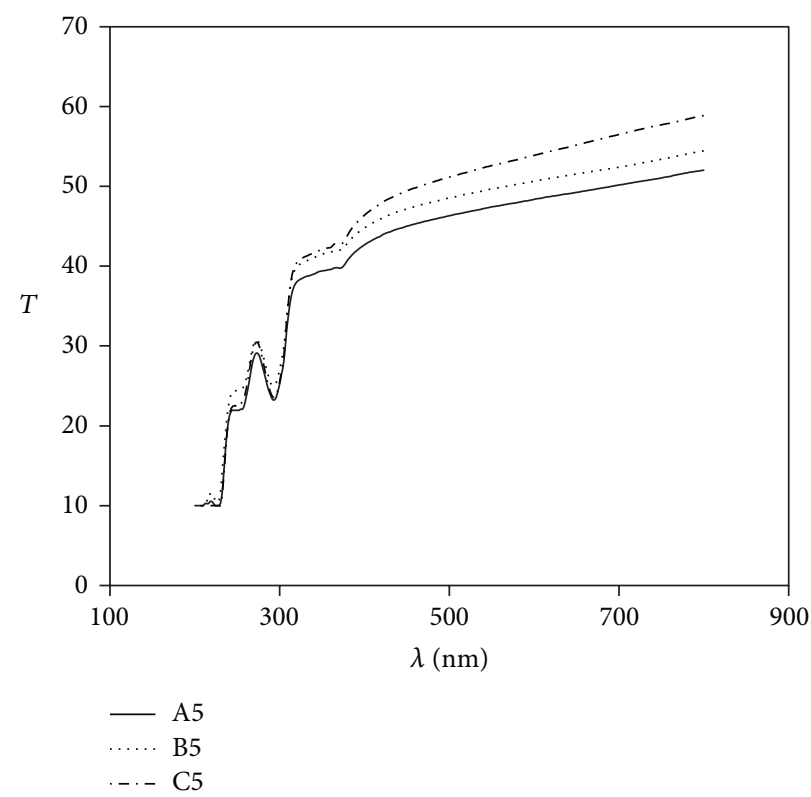

(c)

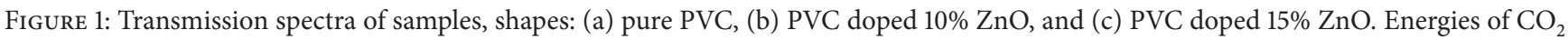
Laser: (A) $300 \mathrm{~mJ}$, (B) $400 \mathrm{~mJ}$, and (C) $500 \mathrm{~mJ}$ for all shapes.

the objective of this work is to investigate the tuning of optical constants of samples after irradiation by continuous $\mathrm{CO}_{2}$ laser at different energies.

\section{Material and Methods}

The materials used in this work were a powder of PVC doped by nano- $\mathrm{ZnO}$ films and prepared at room temperature by solution casting method. The PVC was dissolved in THF and heated gently in water bath to prevent thermal decomposition of polymer. The polymer was stirred by magnetic stirrer until being completely dissolved. The nano- $\mathrm{ZnO}$ with two ratios (10 and 15\%) was added to the polymer solution and heated for a while until being completely dissolved. The solution was poured into glass plate and left to dry for $24 \mathrm{~h}$ to remove any residual solvent. The thickness of the films ranged from 30 to $35 \mu \mathrm{m}$, and thickness measurements were made using electronic digital caliper.

The optical absorbance $(A)$ of the samples was measured as a function of wavelength $(\lambda)$ at the range of $200-800 \mathrm{~nm}$ by using computerized Shimadzu UV-Vis 160A ultraviolet spectrophotometer with full scale absorbance up to 2.5 . 


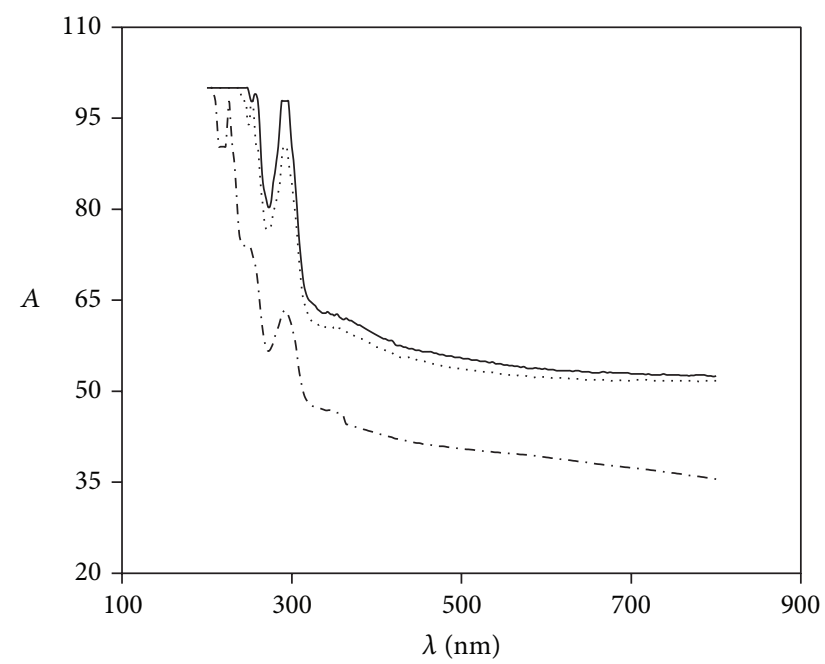

$-\mathrm{A} 1$

…. B1

$\cdot-\cdot-\mathrm{C} 1$

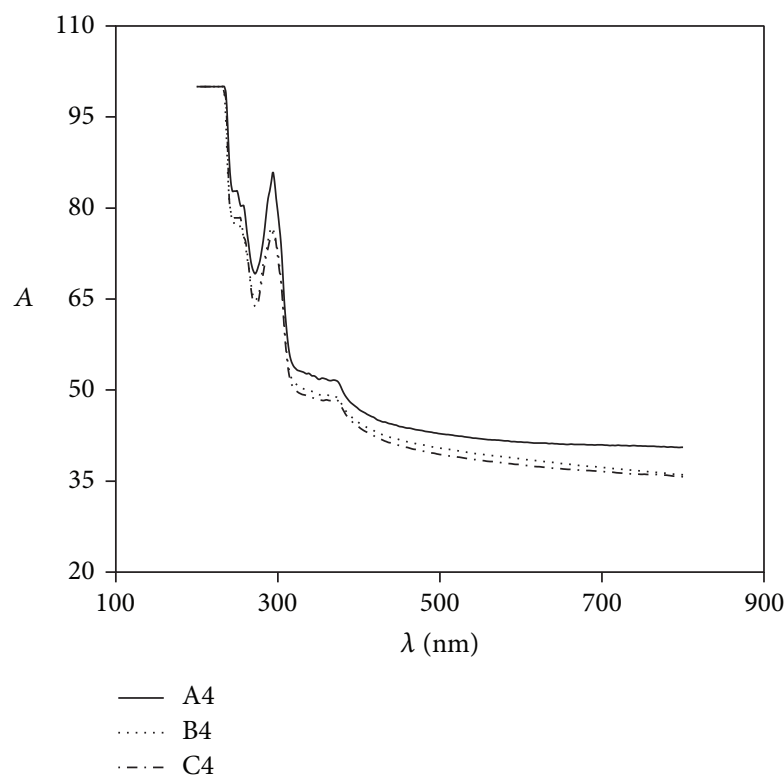

(b)

(a)

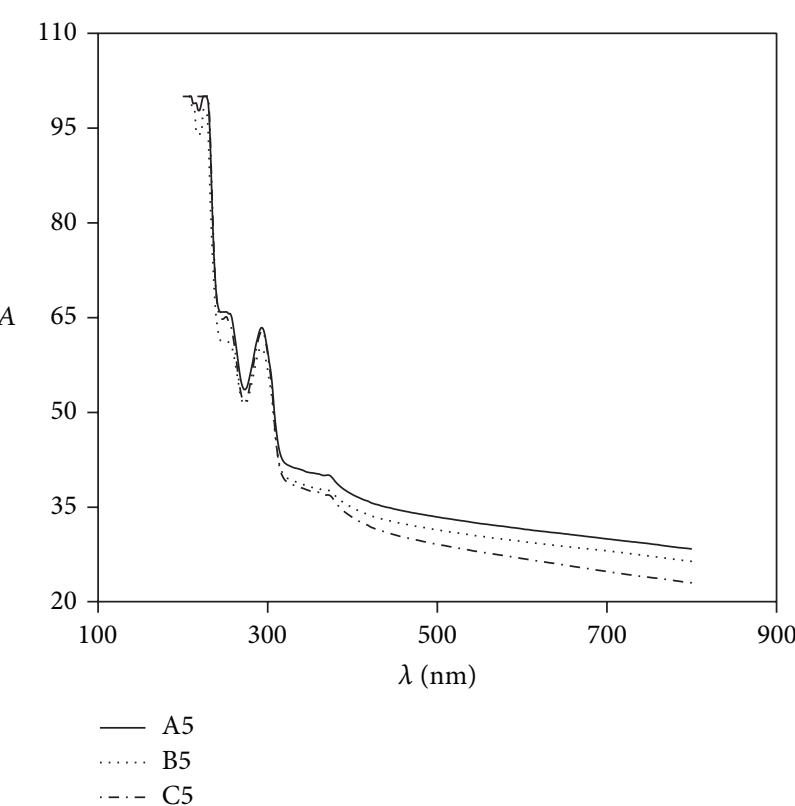

(c)

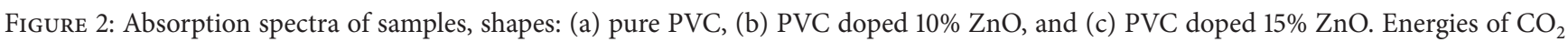
Laser: (A) $300 \mathrm{~mJ}$, (B) $400 \mathrm{~mJ}$, and (C) $500 \mathrm{~mJ}$ for all shapes.

The films were irradiated by continuous $\mathrm{CO}_{2}$ laser at various energies $(300,400$, and $500 \mathrm{~mJ})$. The wavelength of the laser was $10.6 \mathrm{~nm}$; the diameter of laser beam was $100 \mathrm{~nm}$.

\section{Result and Discussion}

The optical transmission spectra $(T)$ of the pure PVC and PVC doped with 10 and $15 \%$ concentrations of nano- $\mathrm{ZnO}$ thin films are shown in Figure 1; the measurements were performed in the wavelength range of $200-800 \mathrm{~nm}$. This figure shows that the transmittance intensity increases with increasing wavelength (Table 1). For pure and doped films, it is observed that integration of $\mathrm{ZnO}$ nanoparticles into PVC matrix increases the transparency of the PVC films. On the other hand, the transmittance intensity of all samples increases with increasing laser power. During laser irradiation, the samples got enough vibration energy that converted to bulk heating and the defects are gradually reduced. The reduction of defects decreases the density of localized states (Urbach energy $\mathrm{Eu}$ ) in the band structure, consequently increasing the optical band gap $\left(E_{q}\right)$, as shown in Table 1 [14].

The absorption spectra $(A)$ of $\mathrm{ZnO}$ doped PVC thin films are illustrated in Figure 2. The exhibit opposite behavior 


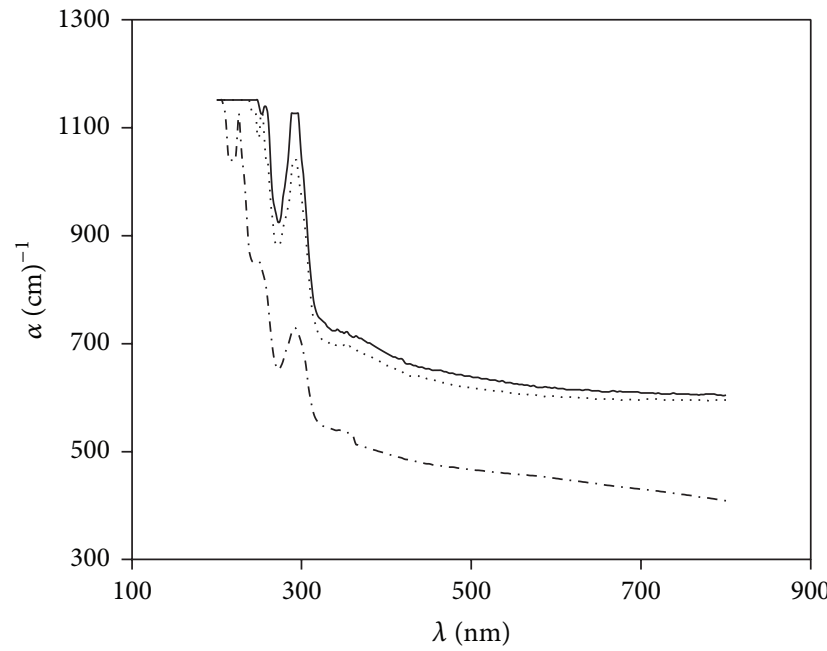

$\begin{array}{lll}-\mathrm{A} 1 \\ \cdots & \mathrm{B} 1\end{array}$ $\cdot-\cdot-\mathrm{C} 1$

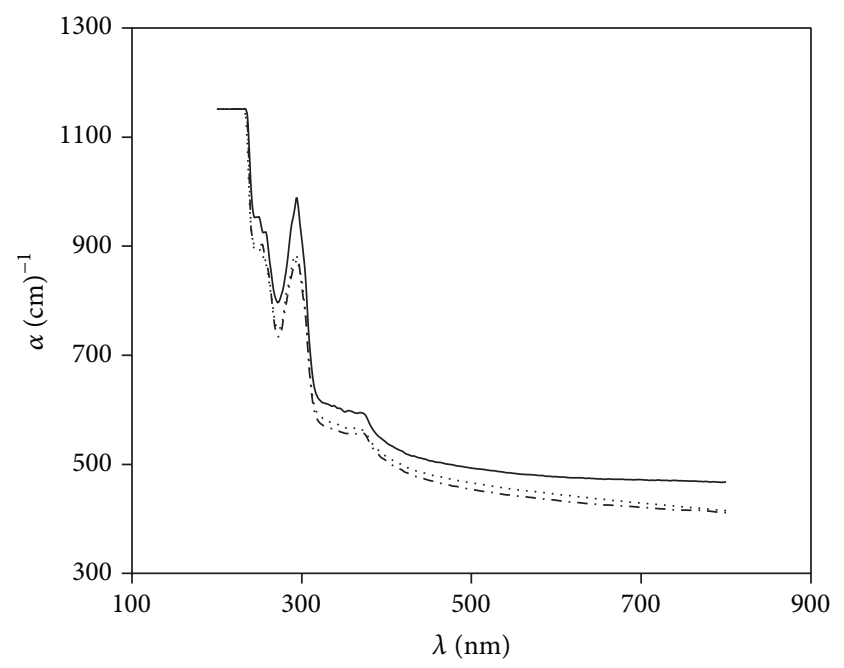

$-\mathrm{A} 4$

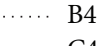

(a)

(b)

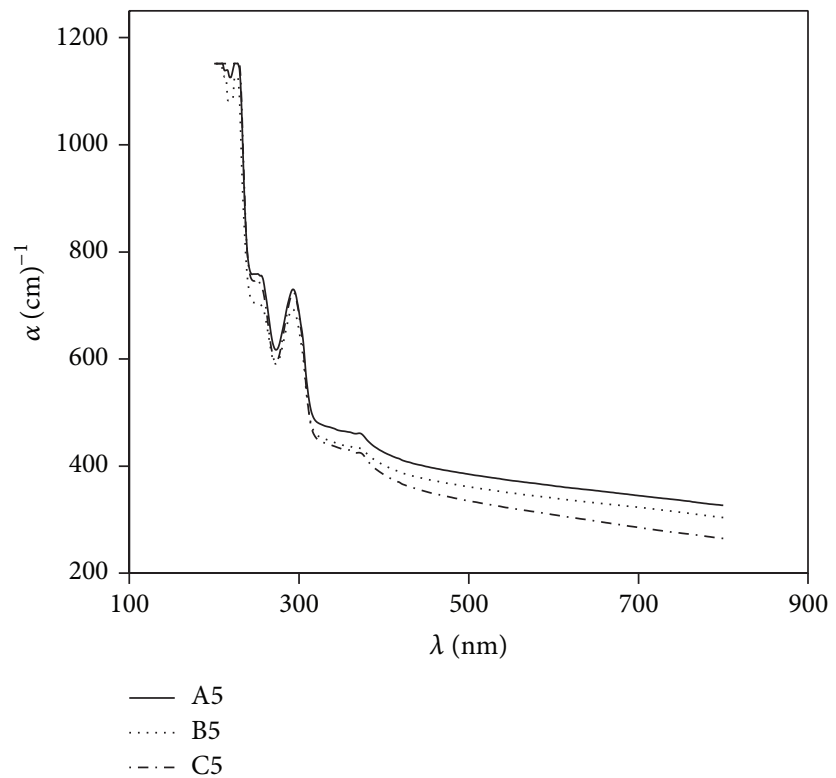

(c)

Figure 3: Absorption coefficient spectra of samples, shapes: (a) pure PVC, (b) PVC doped 10\% ZnO, and (c) PVC doped 15\% ZnO. Energies of $\mathrm{CO}_{2}$ Laser: (A) $300 \mathrm{~mJ}$, (B) $400 \mathrm{~mJ}$, and (C) $500 \mathrm{~mJ}$ for all shapes.

in transmittance spectra. These absorption spectra, which are the most direct and perhaps the simplest method for probing the band structure of materials, are employed in the determination of the energy gap $E_{g}$. The films show a decrease in absorbance with the increasing of the applied $\mathrm{CO}_{2}$ laser power. It was found that the absorption edge shifts towards higher energies (shorter wavelengths); this shift is called Moss-Burstein effect [15]. The figure revealed that the absorbance decreases. This is due to the increasing optical absorption and the increasing attenuation of incident beam [16].
The variation of the optical absorption coefficient $\alpha$ with wavelength is a unique parameter of the medium; it provides the most valuable optical information available for material identification. The absorption coefficient $(\alpha)$ was calculated by using the following equation [17]:

$$
\alpha=\frac{1}{d} \ln \frac{1}{T}=\frac{A}{d}
$$

where $d$ is the sample thickness. Figure 3 shows the dependence of the absorption coefficient on the wavelength for 


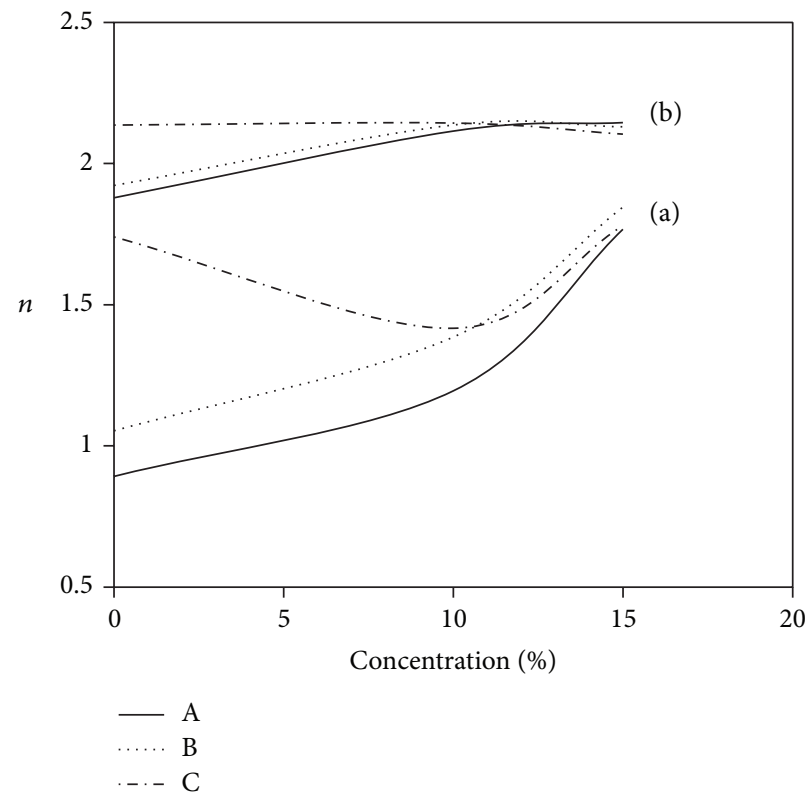

Figure 4: The variation of refractive index versus different concentrations of $\mathrm{ZnO}$ in PVC: (A) $300 \mathrm{~mJ}$, (B) $400 \mathrm{~mJ}$, and (C) $500 \mathrm{~mJ}$. At specific wavelengths (a) $300 \mathrm{~nm}$, (b) $500 \mathrm{~nm}$.

TABLE 1: Optical constants of samples.

\begin{tabular}{lccc}
\hline Samples & $T \%$ & $E_{g}(\mathrm{eV})$ & $E_{u}(\mathrm{eV})$ \\
\hline (Pure) A1 & 29.8426 & 3.79 & 0.13 \\
(Pure) B1 & 30.3956 & 3.8 & 0.11 \\
(Pure) C1 & 44.1459 & 3.81 & 0.08 \\
$(10 \%)$ A4 & 39.2794 & 3.823 & 0.09 \\
$(10 \%)$ B4 & 43.6029 & 3.83 & 0.06 \\
$(10 \%)$ C4 & 43.9279 & 3.831 & 0.13 \\
$(15 \%)$ A5 & 52.0137 & 5.08 & 0.14 \\
$(15 \%)$ B5 & 54.4400 & 5.14 & 0.12 \\
$(15 \%)$ C5 & 58.8598 & 5.07 & 0.18 \\
\hline
\end{tabular}

the pure samples and with different concentrations of nano$\mathrm{ZnO}$ after being irradiated with specific laser power (300, 400 , and $500 \mathrm{~mJ}$ ); the absorption coefficient decreases with the increase of wavelength and $\mathrm{CO}_{2}$ laser power.

To complete the fundamental study of the optical behavior of prepared samples, it is quite important to pay attention to the refractive index $(n)$, which could be determined from the absolute values of the transmittance and reflectance of the investigated films using the following formula [18]:

$$
n=\left[\frac{1+R}{1-R}\right]+\left[\frac{4 R}{(1-R)^{2}}-k^{2}\right]^{1 / 2},
$$

where $k$ is the extinction coefficient and $R$ is the optical reflectance.

Figure 4 represents the variation between refractive index and concentration for the doped polymers films in two specific wavelengths (300 and $500 \mathrm{~nm}$ ), for all compositions (pure, 10, and 15\%); the refractive index increases with increasing $\mathrm{CO}_{2}$ laser energy. The figure shows that the refractive index increases as a result of increasing the percentage of $\mathrm{ZnO}$; this behavior can be attributed to the increase of the packing density as a result of filler content [18]. The polymers with high refractive index are very useful in optics and photonics due to their ability to reduce reflection losses at interfaces and, hence, increase light output [19].

The extinction coefficient can be obtained from the following relation [18]:

$$
k=\frac{\alpha \lambda}{4 \pi} .
$$

Plots in Figure 5 represent the dispersion in the extinction coefficient for the doped polymers films in the investigated range of wavelengths. Inspection of Figure 5 indicates for all compositions that the extinction coefficient increases with increasing wavelength. The figure also shows that extinction coefficient decreases as a result of increasing the percentage of $\mathrm{ZnO}$ and irradiation laser power. Such behavior was observed in the absorption coefficient, which means that the extinction coefficient is absorption coefficient related according to (3) [20].

Figure 6 shows the variation of optical conductivity $(\sigma)$ with wavelength for all samples, shapes (a), (b), and (c), the optical conductivity can be calculated from the following formula [21]:

$$
\sigma=\frac{\alpha n c}{4 \pi},
$$

where $c$ is the velocity of light. It is clear from the figure that the values of optical conductivity were decreased with the increase of concentrations of nano- $\mathrm{ZnO}$ and the increase of irradiation laser power too. 


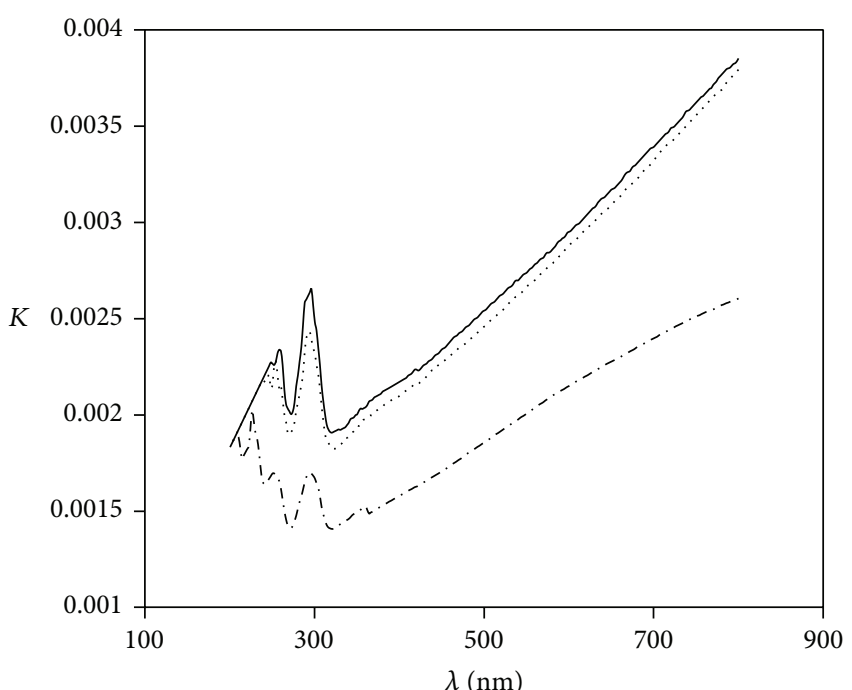

$\begin{array}{ll}\ldots & \mathrm{A} 1 \\ \ldots . & \mathrm{B} 1 \\ \ldots & \mathrm{C} 1\end{array}$

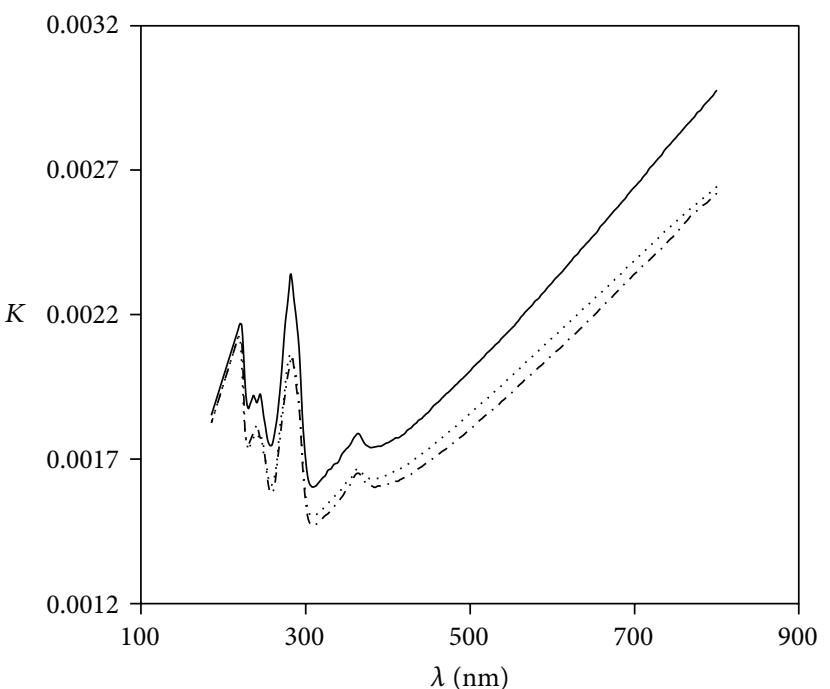

- A4

…. B 4

$\cdot-\cdot-\mathrm{C} 4$

(a)

(b)

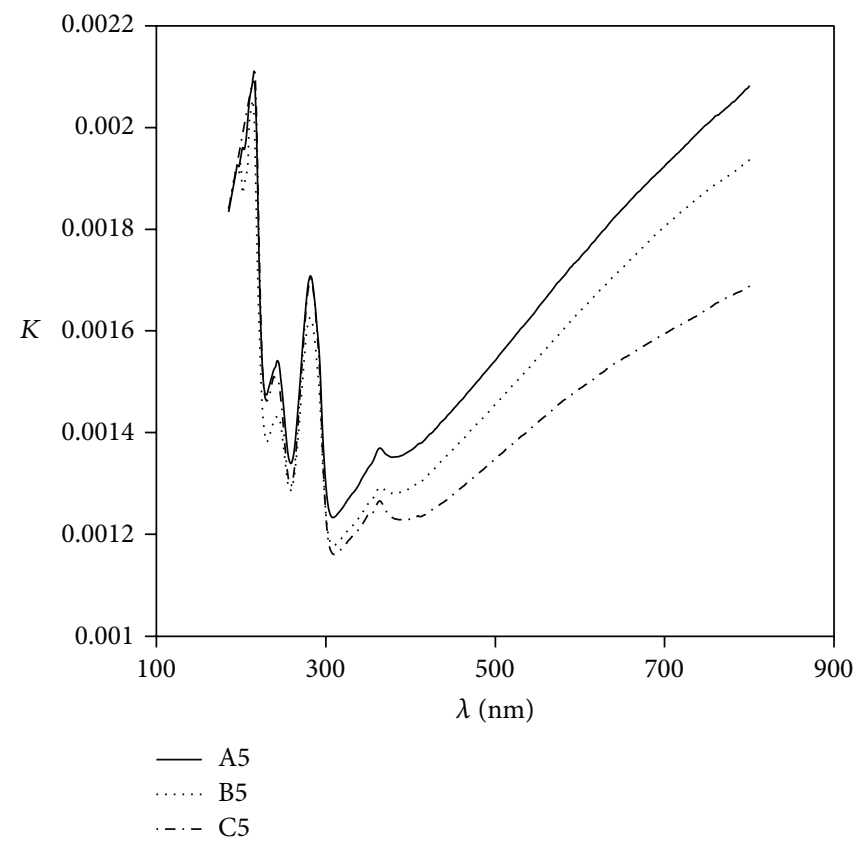

(c)

Figure 5: Extinction coefficient spectra of samples, shapes: (a) pure PVC, (b) PVC doped 10\% ZnO, and (c) PVC doped 15\% ZnO. Energies of $\mathrm{CO}_{2}$ Laser: (A) $300 \mathrm{~mJ}$, (B) $400 \mathrm{~mJ}$, and (C) $500 \mathrm{~mJ}$ for all shapes.

\section{Conclusions}

Nanocomposite films of $\mathrm{ZnO}$ nanoparticles doped PVC polymer have been successfully prepared using casting method technique. The prepared samples have been irradiated by continuous $\mathrm{CO}_{2}$ laser at three different energies for 60 seconds. The optical properties were studied by using spectrophotometer. Transmittance, energy gap, and refractive index of these films were observed to increase with the increase of irradiation energy. Other optical properties (absorption, Urbach energy, absorption coefficient, extinction coefficient, and optical conductivity) showed different behavior, which decreased with the increase in laser energy. These results indicate that the optical properties of these samples were sensitive to IR radiation and can be easily modulated under the influence of laser light. 

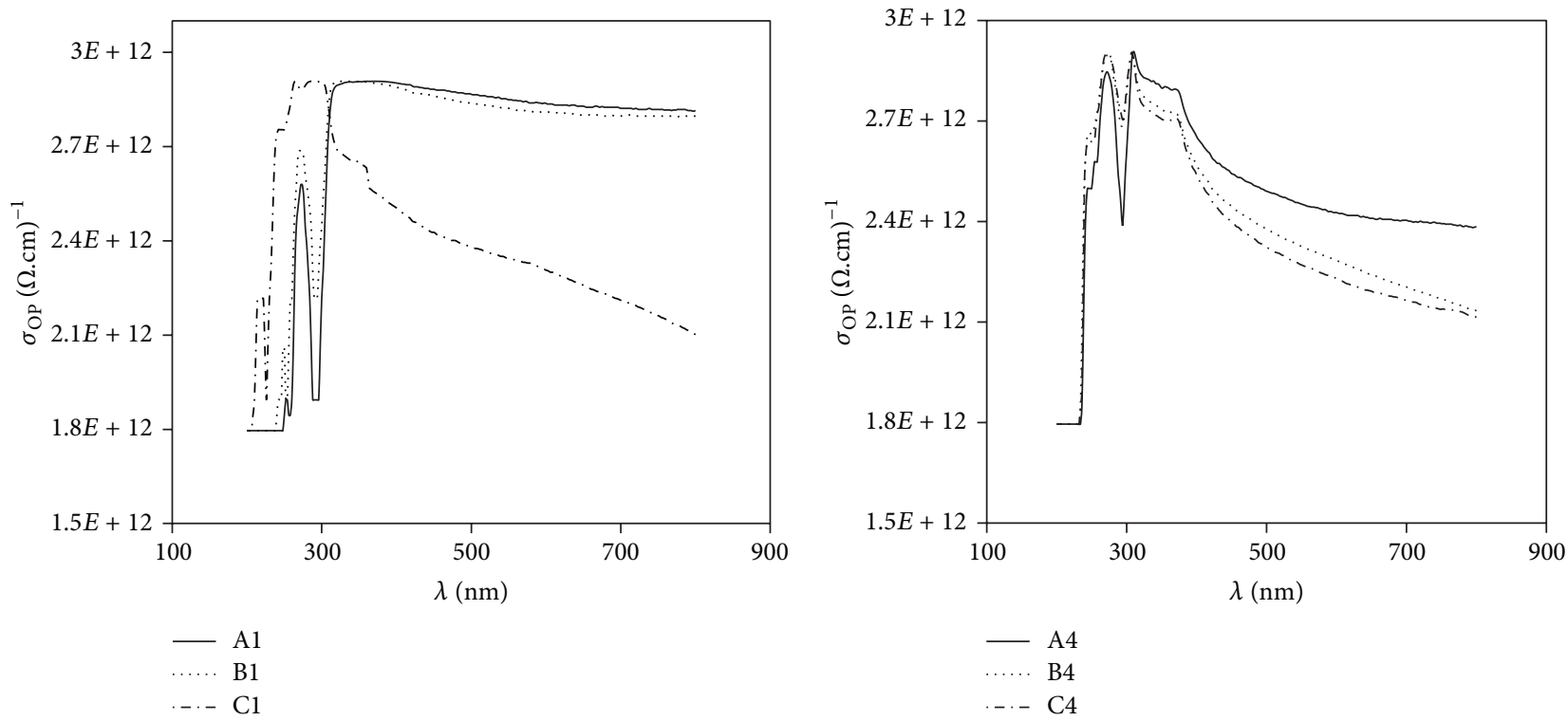

(a)

(b)

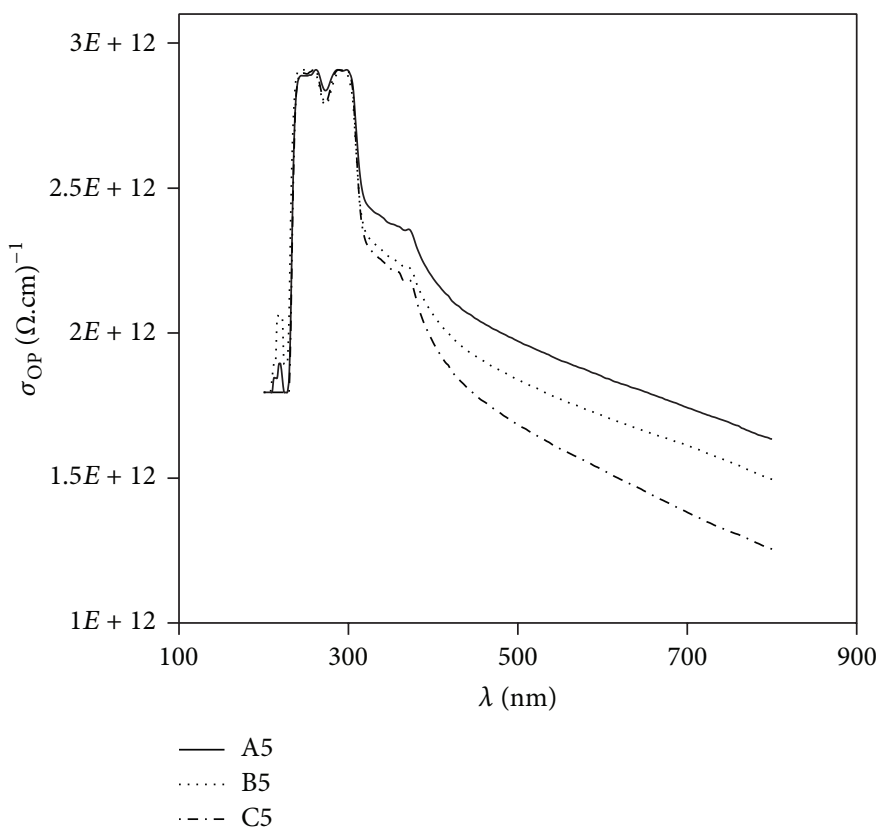

(c)

Figure 6: Optical conductivity spectra of samples, shapes: (a) pure PVC, (b) PVC doped 10\% ZnO, and (c) PVC doped 15\% ZnO. Energies of $\mathrm{CO}_{2}$ Laser: (A) $300 \mathrm{~mJ}$, (B) $400 \mathrm{~mJ}$, and (C) $500 \mathrm{~mJ}$ for all shapes.

\section{Conflict of Interests}

The authors declare that there is no conflict of interests regarding the publication of this paper.

\section{Acknowledgments}

The authors thank Al-Nahrain University and Universiti Kebangsaan Malaysia for the funding (Codes AP-2011 17, DPP2013-054, UKM-MI-OUP-2011, AP-2012-017, and DLP 2013002).

\section{References}

[1] D. Y. Godovsky, "Device applications of polymer-nanocomposites," Advances in Polymer Science, vol. 153, pp. 163-205, 2000.

[2] F. A. Kasim, M. A. Mahdi, J. J. Hassan, S. K. J. Al-Ani, and S. J. Kasim, "Preparation and optical properties of CdS/Epoxy nanocomposites," International Journal of Nanoelectronics and Materials, vol. 5, no. 1, pp. 57-66, 2012.

[3] S. Tachikawa, A. Noguchi, T. Tsuge, M. Hara, O. Odawara, and H. Wada, "Optical properties of $\mathrm{ZnO}$ nanoparticles capped with polymers," Materials, vol. 4, no. 6, pp. 1132-1143, 2011. 
[4] P. Obreja, D. Cristea, M. Purica, R. Gavrila, and F. Comanescu, "Polymers doped with metal oxide nanoparticles with controlled refractive index," Polimery, vol. 52, no. 9, pp. 679-685, 2007.

[5] A. Patsidis and G. C. Psarras, "Dielectric behaviour and functionality of polymer matrix ceramic $\mathrm{BaTiO}_{3}$ composites," Express Polymer Letters, vol. 2, no. 10, pp. 718-726, 2008.

[6] R. M. Ahmed and S. M. El-Bashir, "Structure and physical properties of polymer composite films doped with fullerene nanoparticles," International Journal of Photoenergy, vol. 2011, Article ID 801409, 6 pages, 2011.

[7] Y.-J. Lee, D. S. Ruby, D. W. Peters, B. B. McKenzie, and J. W. Hsu, "ZnO nanostructures as efficient antireflection layers in solar cells," Nano Letters, vol. 8, no. 5, pp. 1501-1505, 2008.

[8] K. Vanheusden, C. H. Seager, W. L. Warren, D. R. Tallant, and J. A. Voigt, "Correlation between photoluminescence and oxygen vacancies in $\mathrm{ZnO}$ phosphors," Applied Physics Letters, vol. 68, no. 3, pp. 403-405, 1996.

[9] C. R. Gorla, N. W. Emanetoglu, S. Liang et al., "Structural, optical, and surface acoustic wave properties of epitaxial $\mathrm{ZnO}$ films grown on (0112) sapphire by metalorganic chemical vapor deposition," Journal of Applied Physics, vol. 85, no. 16, pp. 25952602, 1999.

[10] Z. K. Tang, G. K. L. Wong, P. Yu et al., "Room-temperature ultraviolet laser emission from self-assembled $\mathrm{ZnO}$ microcrystallite thin films," Applied Physics Letters, vol. 72, no. 17, pp. 3270-3272, 1998.

[11] D. C. Reynolds, D. C. Look, and B. Jogai, "Optically pumped ultraviolet lasing from ZnO," Solid State Communications, vol. 99, no. 12, pp. 873-875, 1996.

[12] Q. Liu, K. S. Chiang, L. Reekie, and Y. T. Chow, " $\mathrm{CO}_{2}$ laser induced refractive index changes in optical polymers," Optics Express, vol. 20, no. 1, pp. 576-582, 2012.

[13] Q. Liu and K. S. Chiang, " $\mathrm{CO}_{2}$-laser writing of polymer longperiod waveguide gratings," in Proceedings of the IEEE Conference on Photonics Global, pp. C62-C65, Institute of Electrical and Electronics Engineers, Singapore, December 2008.

[14] L. M. Rahman, "Study the effect of heating annealing on some optical properties of ZnSe thin film," Tikrit Journal of Pure Science, vol. 16, no. 2, pp. 218-224, 2011.

[15] S. S. Zakariyah, P. P. Conway, D. A. Hutt et al., "Polymer optical waveguide fabrication using laser ablation," in Proceedings of the IEEE Conference on Electronics Packaging Technology, pp. 936941, Institute of Electrical and Electronics Engineers, Singapore, December 2009.

[16] L. Ç. Özcan, F. Guay, R. Kashyap, and L. Martinu, "Investigation of refractive index modifications in $\mathrm{CW} \mathrm{CO}_{2}$ laser written planar optical waveguides," Optics Communications, vol. 281, no. 14, pp. 3686-3690, 2008.

[17] S. G. khalil, M. A. Ameen, and N. J. Jubier, "Eeffect of laser irradiation on the optcial properties of $\mathrm{SnO}_{2}$ films deposited by post oxidation of metal films," Baghdad Science Journal, vol. 8, no. 4, 2011.

[18] D. Sumangala, D. Amma, V. K. Vaidyan, and P. K. Manoj, "Structural, electrical and optical studies on chemically deposited tin oxide films from inorganic precursors," Materials Chemistry and Physics, vol. 93, no. 1, pp. 194-201, 2005.

[19] P. Obreja, M. Kusko, D. Cristea, M. Purica, and F. Comanescu, "Doped polymers controllable indexe-preparation, processing and applications," in Proceedings of the Symposium on Photonics Technologies for 7th Framework Program, pp. 392-395, Wrocław, Poland, October 2006.
[20] A. A. Naimi and M. F. Naimi, "Studying the optical properties cadmium stunet $\mathrm{Cd}_{2} \mathrm{SnO}_{4}$ thin films prepared by spray pyrolysis technique," Engineering \& Technology Journal, vol. 27, no. 14, pp. 445-456, 2009.

[21] R. L. Mishra and S. K. Mishra, "Optical and gas sensing characteristics of tin oxide nano-crystalline thin film," Journal of Ovonic Research, vol. 5, no. 4, pp. 77-85, 2009. 

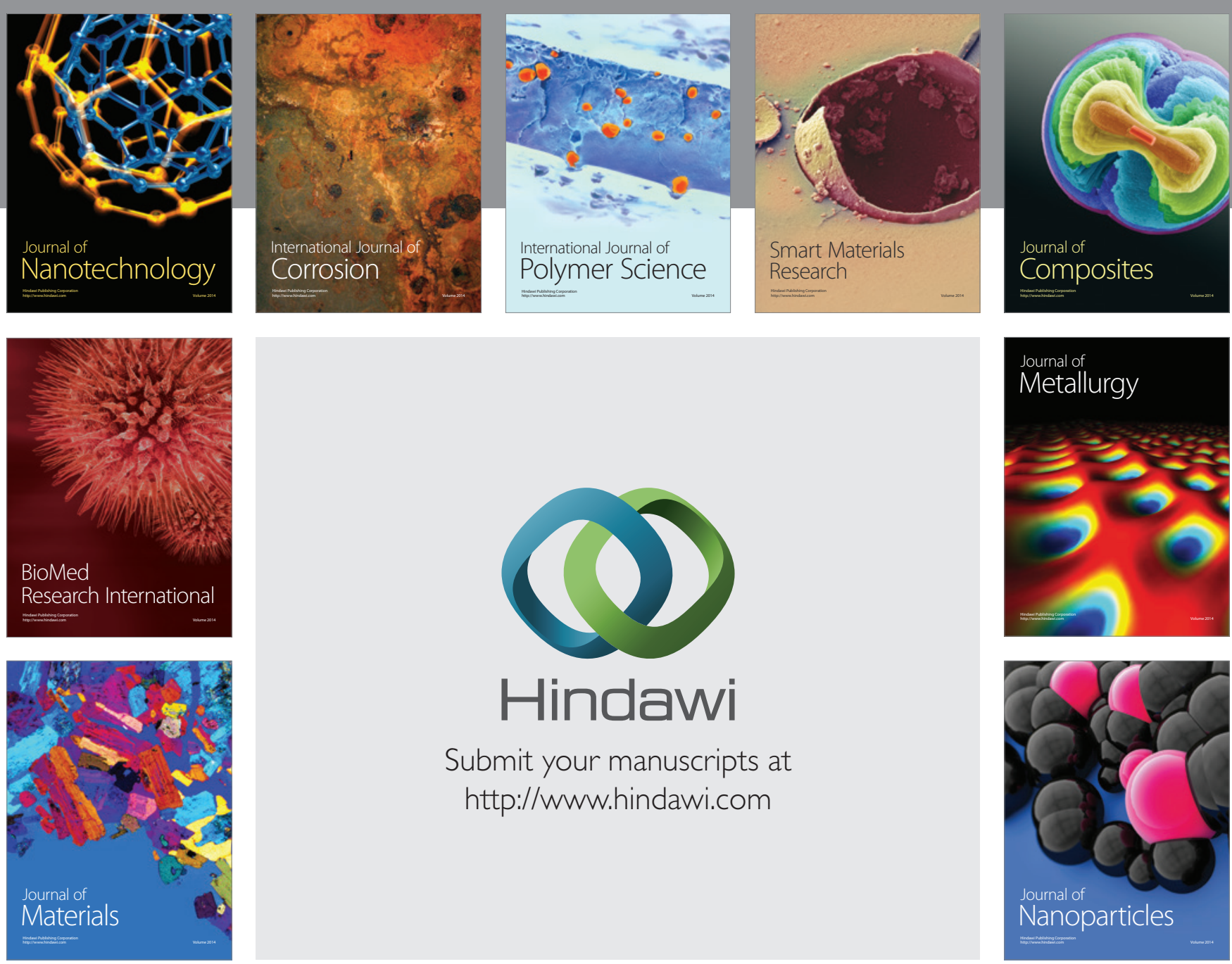

Submit your manuscripts at http://www.hindawi.com
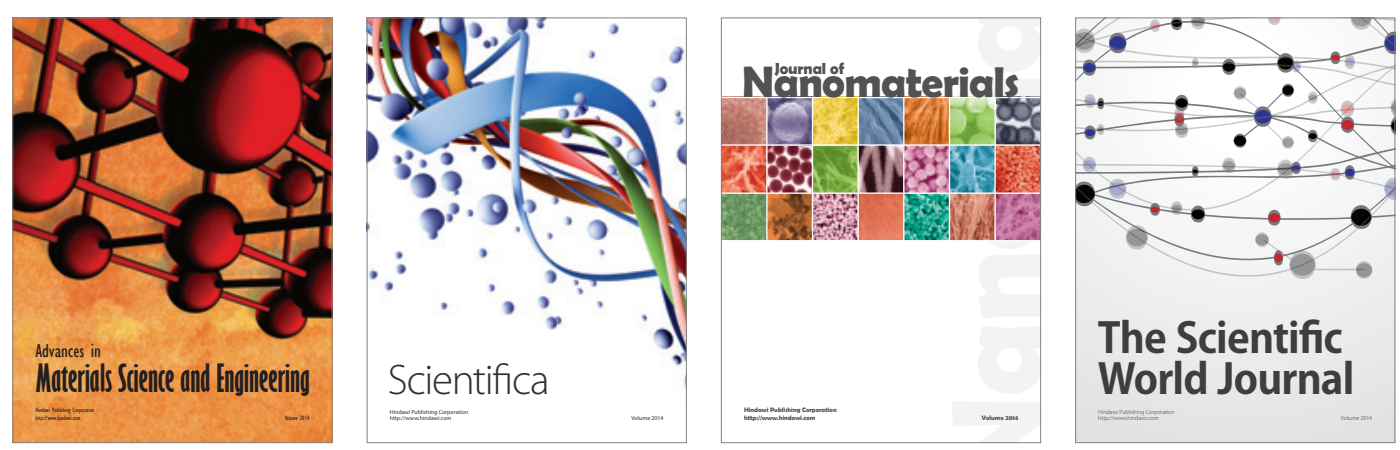

\section{The Scientific World Journal}
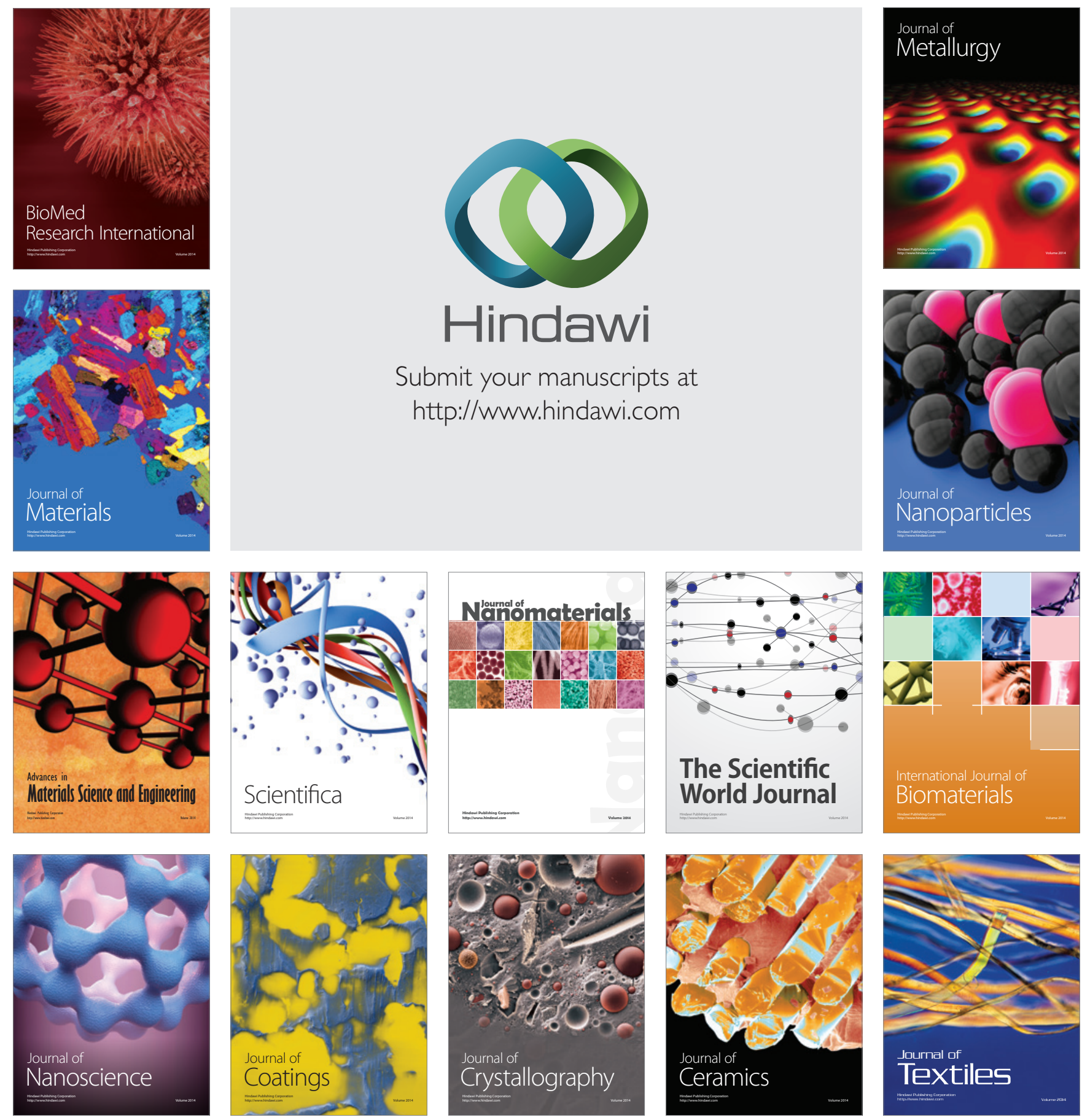